\title{
Hysteretic Behavior of Eccentrically Loaded Reinforced Air-Entrained Concrete Columns under Combined Effects of Freeze-Thaw Cycles and Seawater Corrosion
}

\author{
Jieqiong Wu $\mathbb{D}^{1},{ }^{1}$ Jian Zhang, ${ }^{1}$ Bo Diao $\mathbb{D}^{1,2}$ Shaohong Cheng $\mathbb{D},{ }^{3}$ and Yinghua Ye $\mathbb{D}^{1}$ \\ ${ }^{1}$ School of Transportation Science and Engineering, Beihang University, Beijing 100083, China \\ ${ }^{2}$ State Key Laboratory of Subtropical Building Science, South China University of Technology, Guangzhou 510640, China \\ ${ }^{3}$ Department of Civil and Environmental Engineering, University of Windsor, Windsor, ON, Canada N9B 3P4
}

Correspondence should be addressed to Bo Diao; diaobo@buaa.edu.cn

Received 3 December 2017; Accepted 21 May 2018; Published 19 July 2018

Academic Editor: Luigi Di Sarno

Copyright (c) 2018 Jieqiong Wu et al. This is an open access article distributed under the Creative Commons Attribution License, which permits unrestricted use, distribution, and reproduction in any medium, provided the original work is properly cited.

Besides service loads, reinforced concrete structures in cold coastal seismic regions are subjected to multiple attacks of freeze-thaw cycles and seawater corrosion as well as the earthquake struck. An experimental study was conducted to investigate the seismic response of eccentrically loaded reinforced air-entrained concrete columns under alternative actions of freeze-thaw cycles and chloride corrosion. Results show that, after 300 times of freeze-thaw cycles alternated with 100 times of seawater immersion, the hysteretic behavior of the eccentrically loaded columns manifested an apparent asymmetric pattern. Under forward cyclic load, the existence of larger eccentric load rendered the reduction of the ultimate load and the ductility of a column by up to $20.3 \%$ and $46.05 \%$, respectively, but it had a positive effect if reverse cyclic load was applied. The presence of eccentric load could have a considerable impact on the seismic behavior of reinforced air-entrained concrete columns served in an aggressive environment.

\section{Introduction}

Reinforced concrete (RC) structures in cold coastal regions or deicing environment are usually subjected to multiple attacks of freeze-thaw cycles, chloride ion corrosion, and service loads. The existence of cracks induced by working load would facilitate the penetration of seawater into concrete to reach and corrode reinforcements $[1,2]$ and thus weaken the bond behaviors between concrete and reinforcing bars [3, 4]. Corrosion of steel reinforcement combined with the deterioration of concrete properties would weaken the loadbearing capacity of structures and have an adverse impact on their durability $[5,6]$. In particular, structures in seismic regions would be more vulnerable to earthquake.

In the past few decades, a majority of the research focused on the performance degradation of concrete and steel bars in the environment of freeze-thaw cycles and chloride corrosion $[7,8]$. Solutions as to limit water-cement ratio, to increase concrete cover thickness, and to apply air-entrained concrete were proposed [8]. In particular, the study of Hale et al. [9] had shown that concrete having a water-cement ratio between 0.36 and 0.50 and an air content of $4 \%$ would be sufficient to resist frost.

The durability studies of RC structures are mainly related to the corrosion of reinforcing bars and its impact on the structural behavior $[3,4,10]$. The corrosion damage of an $\mathrm{RC}$ beam exposed to the marine environment for 40 years was evaluated by Poupard et al. [5]. A diameter loss of about $30 \%$ was noted on the tensile reinforcement, while that of the compressive reinforcing bars was less than $2 \%$. This was a clear indication that more significant corrosion occurred on tension bars than compression bars. The experimental results by Giordano et al. [11] showed that both chemical corrosion and applied cyclic load contributed to the deterioration of RC structural performance. A typical aging RC bridge was investigated by Simon et al. [12], and it was found that its seismic resistance and ductility were marginally affected by the corrosion. 
Eccentric compression columns are more commonly encountered in engineering practice [13]. The durability of eccentric compression columns has been addressed in the existing studies. Gong et al. [14] and Shi et al. [15] investigated the performance of electrochemically corroded and eccentrically loaded RC columns. Results showed that, with the increase of reinforcement corrosion ratio, the ultimate load, stiffness, and ductility of the columns all decreased. Shen et al. [16] investigated the chloride diffusivity and mechanical behavior of RC columns under the combined action of freeze-thaw cycles, seawater immersion, and sustained eccentric compression load. It was found that when the crack width was more than $0.11 \mathrm{~mm}$, chloride ingress was accelerated, and both yield load and ultimate load of the RC columns decreased as crack width increased. Li [17] applied sustained eccentric compression load with a rate of $0,0.3$, and 0.6 , respectively, on $\mathrm{RC}$ columns. The test results showed that the sustained load had no obvious effect when the eccentricity was $100 \mathrm{~mm}$. Diao et al. [18] experimentally studied the effects of freeze-thaw cycles and seawater corrosion on the structural behavior of reinforced air-entrained concrete beams under persistent loads with ratios of $0,0.3$, and 0.5 , respectively. Results showed that the presence of persistent loads aggravated the structural behavior, and when the ratio was 0.5 , the ultimate load and ductility were significantly reduced.

RC structures under cold coastal environments are usually exposed to freeze-thaw cycles, seawater immersion, and service load. But the studies of the combined effect of these three factors on RC columns are fewer. Furthermore, structures in seismic regions are also subjected to earthquake struck, and the hysteretic behavior of RC structures under cold coastal environments is lacking in existing literature. In the current paper, an experimental study was conducted to investigate the hysteretic behavior of reinforced airentrained concrete columns under alternative actions of freeze-thaw cycles and seawater corrosion when subjected to persistent eccentric compressive load. The crack development of the studied columns during the process of multiple attacks was also examined. The results are expected to be contributed to the durability design of reinforced concrete structures in cold coastal seismic regions.

\section{Experimental Details}

2.1. Specimens. Five reinforced air-entrained concrete columns, named Col-0 to Col-4, with the same sizes and same reinforcements were made. The concrete mixture included 325 Portland cement, river sand, coarse aggregates with a maximum size of $10 \mathrm{~mm}$, and Type II fly ash. In addition, water-reducing and air-entraining admixtures were added to the mixture with a water-cement ratio of 0.4 and an air content of 5.9\%. Plain round steel bars with $10 \mathrm{~mm}$ diameter were used as the longitudinal reinforcements with yield and ultimate strengths of $250 \mathrm{MPa}$ and $360 \mathrm{MPa}$, respectively, whereas $6 \mathrm{~mm}$ plain round steel bars with a yield strength of $280 \mathrm{MPa}$ and an ultimate strength of $400 \mathrm{MPa}$ were used as the stirrups. The geometric dimensions and reinforcement arrangement of the column specimen are shown in Figure 1.
The total length of the column was $800 \mathrm{~mm}$. The middle portion of the column had a square cross section of $120 \mathrm{~mm} \times 120 \mathrm{~mm}$. The four longitudinal reinforcing bars were arranged symmetrically at the four corners of the section. The double leg stirrup had a spacing of $90 \mathrm{~mm}$. The thickness of the concrete cover was $25 \mathrm{~mm}$. To apply eccentric compressive load, brackets were designed for both column ends. The loading eccentricity was $100 \mathrm{~mm}$.

2.2. Testing Cases. The testing conditions of the five reinforced air-entrained concrete columns, that is, the magnitude of eccentric compressive load and exposure conditions to the corrosive media, are listed in Table 1. Eccentric compressive bearing capacity of Col- 0 was tested at the age of 28 days without the application of freeze-thaw cycles and seawater immersion, and its ultimate load was denoted as $P_{\mathrm{u}}$. In order to investigate the impact of low cyclic load on the behavior of a reinforced air-entrained concrete column, Col1 was tested only under low cyclic load at the age of 128 days without the application of freeze-thaw cycles, seawater immersion, and sustained eccentric compressive load. An eccentric compressive load with the magnitude of $0.2 P_{\mathrm{u}}$ and $0.35 P_{\mathrm{u}}$ was applied to Col-3 and Col-4, respectively, and sustained for 100 days before being removed. Then, the columns Col-2, Col-3, and Col-4 were all subjected to a total of 300 times of freeze-thaw cycles alternated with 100 times of seawater immersion. At last, the columns Col-2 to Col-4 were tested at the age of 128 days under low cyclic load.

2.3. Testing Methods. The experimental study was conducted in the Civil Engineering Laboratory at Beihang University, China. The casting and curing conditions were the same as those in the earlier experiment by Diao et al. [6].

According to the Fast Freeze Method specified in the Standard for Test Methods of Long-Term Performance and Durability of Ordinary Concrete (GB/T 50082-2009), a temperature control chamber with the range of temperature variation between $-40^{\circ} \mathrm{C}$ and $+60^{\circ} \mathrm{C}$ was used to apply the freeze-thaw cycles to the specimens. The internal temperature at the center of a concrete specimen was monitored by a temperature sensor embedded in the specimen. Seawater used here was artificially made with $3 \% \mathrm{NaCl}$ (by weight) and $0.34 \% \mathrm{MgSO}_{4}$ (by weight).

To determine the magnitude of the persistent eccentric compressive load applied to Col-3 and Col-4, a static eccentric loading test was conducted on Col-0 at the age of 28 days with an eccentricity of $100 \mathrm{~mm}$ as shown in Figure 2. The ultimate load of Col- 0 was measured to be $P_{\mathrm{u}}=65.1 \mathrm{kN}$, and it failed in a flexural-tensile mode. The relation between the applied eccentric compressive load and the strain in the longitudinal reinforcement was recorded. The setup for applying persistent eccentric compressive load to Col-3 and Col-4 is shown schematically in Figure 3. Two spiral rebars were arranged symmetrically and passed through the brackets at the two ends of the column. By tightening the bolts attached to the two spiral rebars at the specimen ends, persistent eccentric compressive load could be applied to the column. The eccentricity of the load was kept to be the same 


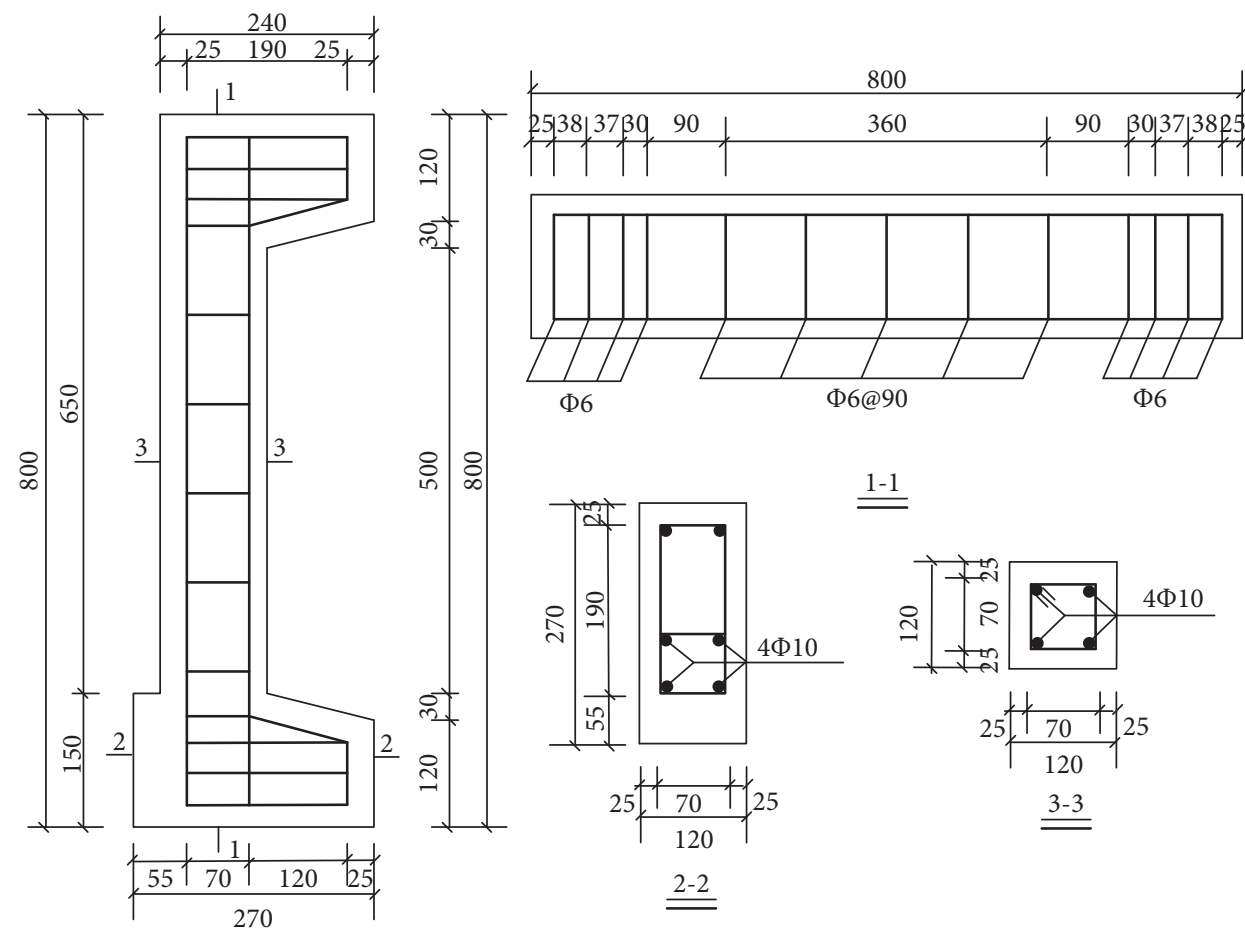

FIGURE 1: Details of reinforced concrete columns (mm).

TABLE 1: Testing conditions of reinforced air-entrained concrete columns.

\begin{tabular}{|c|c|c|c|c|c|}
\hline Group & Col-0 & Col-1 & Col-2 & Col-3 & Col-4 \\
\hline Eccentric compressive load & 0 & 0 & 0 & $0.2 P_{\mathrm{u}}$ & $0.35 P_{\mathrm{u}}$ \\
\hline Number of seawater immersion & 0 & 0 & 100 & 100 & 100 \\
\hline Number of freeze-thaw cycles & 0 & 0 & 300 & 300 & 300 \\
\hline Duration of compressive load & 0 & 0 & 0 & $100 \mathrm{~d}$ & $100 \mathrm{~d}$ \\
\hline Test of loading mode & Monotonic & Cyclic & Cyclic & Cyclic & Cyclic \\
\hline Age at testing & $28 \mathrm{~d}$ & $128 \mathrm{~d}$ & $128 \mathrm{~d}$ & $128 \mathrm{~d}$ & $128 \mathrm{~d}$ \\
\hline
\end{tabular}

$P_{\mathrm{u}}$ is the bearing capacity of Col-0 when subjected to a compressive load with an eccentricity of $100 \mathrm{~mm}\left(P_{\mathrm{u}}=65.1 \mathrm{kN}\right)$.

as that of Col-0, that is, $100 \mathrm{~mm}$. Referring to the strain variation of the longitudinal reinforcement with respect to the magnitude of the eccentric compressive load recorded in Col-0, the magnitude of the persistent eccentric compressive load applied to Col-3 and Col-4 could be controlled by monitoring the strain variation of the reinforcements in these two column specimens.

The variation of the persistent eccentric compressive load was not monitored during freeze-thaw cycles and seawater immersion. To minimize the impact of environmental conditions on the sustained loading system, the bolts and the spiral bars were wrapped with the waterproof material and insulations and sealed with epoxide resin.

After applying the eccentric compressive load to Col-3 and Col-4, these two column specimens along with Col-2 were placed in the temperature control chamber for three freeze-thaw cycles followed by immersing them in the seawater solution for $12 \mathrm{~h}$. The duration of each freeze-thaw cycle lasted for $4 \mathrm{~h}$ including $2.5 \mathrm{~h}$ of freezing and $1.5 \mathrm{~h}$ of thawing. These specimens were subjected to the designed number of freeze-thaw cycles and seawater immersion as listed in Table 1. The simulation process of 300 times of freeze-thaw cycles alternated with 100 times of seawater immersion lasted for 100 days. At the age of 128 days, the persistent loading systems were removed from Col-3 and Col-4. Col-1 to Col-4 were then tested under low cyclic load till failure.

The setup for conducting the low cyclic load test is shown schematically in Figure 4. An axial (vertical) compressive load of $105 \mathrm{kN}$ was applied to the testing column prior to the horizontal cyclic load. The axial compression ratio of the columns was 0.19 . The horizontal displacements at the top and the bottom of the column specimen were measured by the displacement sensors. The horizontal low cyclic load and the vertical compressive load were measured by the force sensors. The entire loading process of the low cyclic test was controlled by the TUST software, and the data were automatically recorded by the IMP data acquisition system.

\section{Testing Results}

3.1. Development of Concrete Crack. At the age of 28 days, eccentric compressive load was applied to Col-3 and Col-4, with a magnitude of $0.2 P_{\mathrm{u}}$ and $0.35 P_{\mathrm{u}}$, respectively. The load 


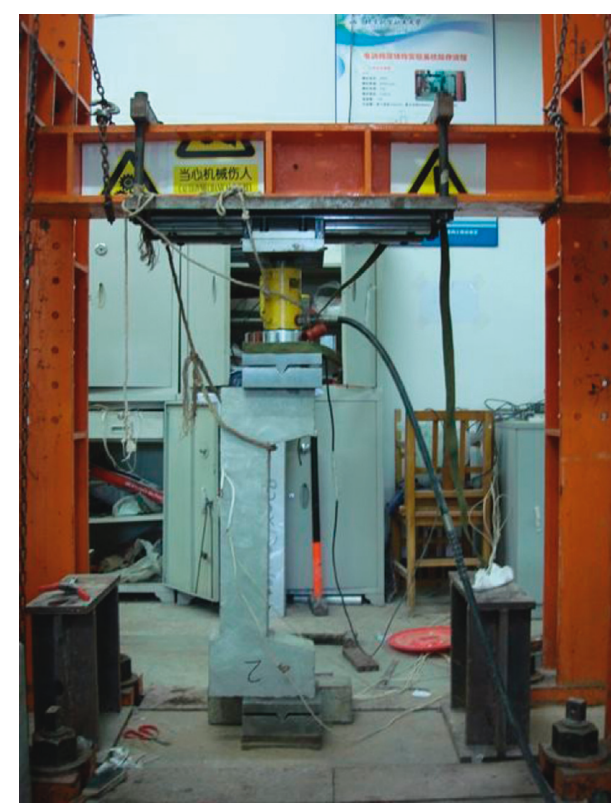

FIgURE 2: Setup of static eccentric loading test.

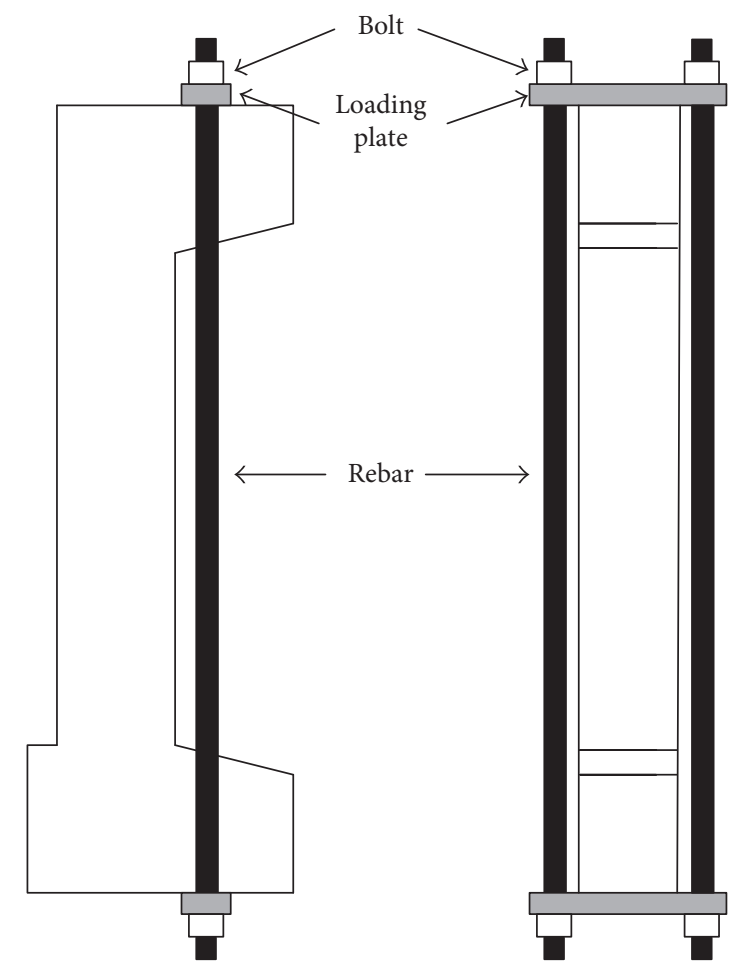

FIGURE 3: Setup for applying persistent compressive load.

was sustained for 100 days and existed during the alternative actions of freeze-thaw cycles and seawater immersion. Initial cracks in Col-3 and Col-4 were mostly distributed on the tensile side of the specimens as expected. Similarly to the study of $\mathrm{Wu}$ et al. [19], the main cracks extended from the tensile surface to just one side of the cross section in Col-3, but they extended to two sides of the cross section in Col-4 which was subjected to higher sustained eccentric compression load than Col-3, as shown in Figures 5(a) and 5(b).

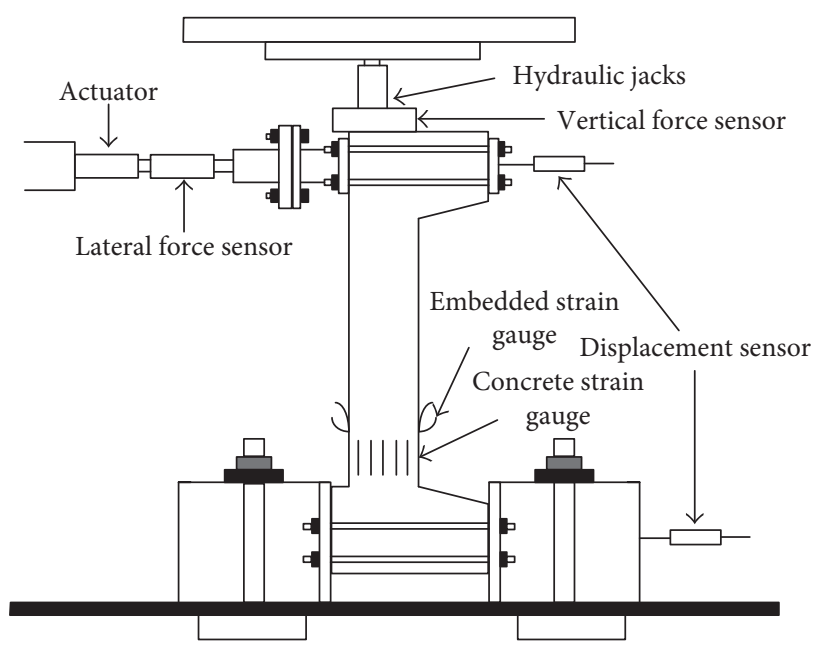

FIGURE 4: Setup of low cyclic loading tests.

Afterwards, alternative freeze-thaw cycles and seawater immersion were applied to these two column specimens, which further promoted the growth of the initial cracks. The development of the initial cracks in Col-3 and Col-4 when subjected to $0,102,201$, and 300 times of freeze-thaw cycles alternated, respectively, with $0,34,67$, and 100 times of seawater immersion is also schematically depicted in Figures 5(a) and 5(b). The number shown next to the crack indicates its width in " $\mathrm{mm}$," and the number in the brackets represents the applied freeze-thaw cycles. For example, for the initial horizontal crack located at the top of the tensile surface of Col-3, the four groups of numbers next to the crack mean that the width of this crack remained at $0.05 \mathrm{~mm}$ after $0,102,201$, and 300 times of freeze-thaw cycles.

As can be seen from Figure 5(a), the exposure to the freeze-thaw attack and seawater corrosion had a minor impact on the crack development in Col-3. During 102 to 201 times of freeze-thaw cycles, the width of the initial cracks showed a relative significant increase. Besides, the initial cracks located closer to the top and bottom of the column tensile surface, which indicated that concrete in this position was vulnerable to sustained eccentric compressive load.

As can be seen from Figure 5(b), the width of the same crack on the tensile surface and the side surfaces was not the same in Col-4, and in the majority of the cases, the same crack grew wider in the tensile surface than in the two side surfaces. Crack widths hardly expanded after alternating 201 times of freeze-thaw cycles with 67 times of seawater immersion, which was similar to the phenomenon of Col-3. During freeze-thaw actions, an inclined crack appeared at the top edge of the column tensile surface. Since this crack would not affect the hysteretic property of the studied column, it is thus not included in the discussion.

It is worth mentioning that, during 102 to 201 times of freeze-thaw cycles and seawater immersion, initial crack width showed a relatively significant increase. A possible explanation was that freeze-thaw cycles would accelerate the development of crack widths, while seawater immersion would contribute to the self-healing of crack widths [20]. 


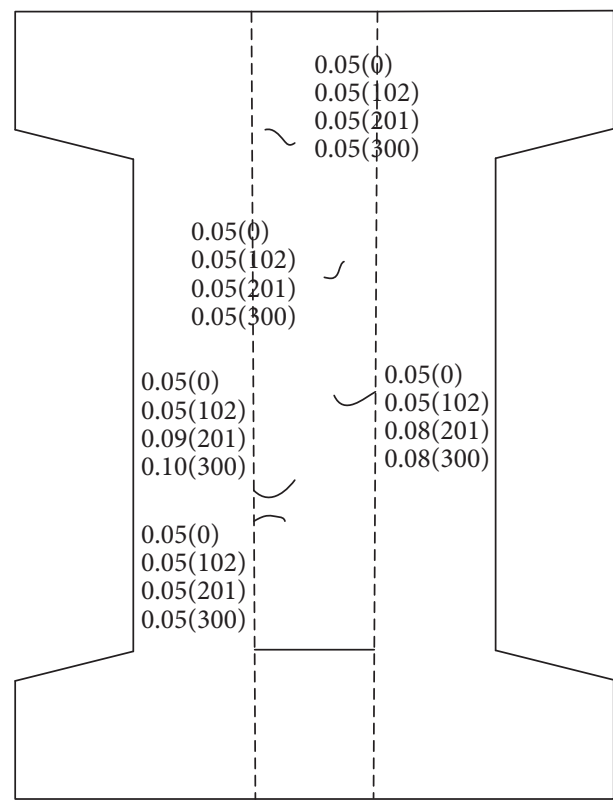

(a)

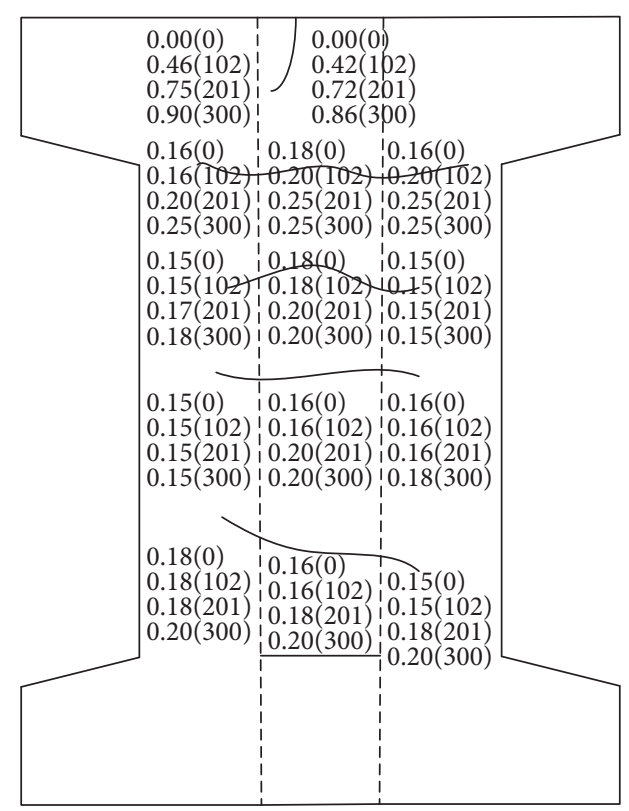

(b)

FIgURE 5: Initial cracks in Col-3 (a) and Col-4 (b) induced by eccentric compressive load and their development due to freeze-thaw cycles and seawater immersion.

\subsection{Impact of Low Cyclic Load}

3.2.1. Failure Mode. After 300 times of freeze-thaw cycles and 100 times of seawater immersion, the persistent eccentric compressive loading systems attached to Col-3 and Col-4 were removed. Subsequently, the low cyclic load test was conducted for Col-1 to Col-4. During the test, the first horizontal tensile cracks were seen to appear near the base of the tensile surface of all four columns when they were loaded in the forward direction; that is, the direction of the horizontal load would induce the same sense of stress and strain distributions as those of the persistent eccentric compressive load. As the magnitude of the controlling horizontal displacement at the top of the column increased, the cracks developed rapidly. All four columns exhibited the ductile failure mode, where the longitudinal tensile reinforcements were yielded first followed by the crush of concrete in the compression zone. The testing results are summarized in Table 2. The detailed experimental observations of these columns were described as follows with typical failure patterns shown in Figure 6.

In Col-1 and Col-2, which were not subjected to persistent loading before, the first horizontal tensile crack was initiated during forward loading on the tensile face near the column base, and it grew rapidly as horizontal displacement at the column top increased. Col-1 and Col-2 manifested the same symmetric failure pattern. To be more specific, the longitudinal tensile reinforcements under forward loading yielded before the concrete in the compression zone crushed, and the conditions of the crushed concrete in the compression zones corresponding to either forward loading or reverse loading were observed to be similar and symmetric on the two sides of the column base. The yield load and the ultimate load of Col-2 were approximately the same as those of Col-1 under forward loading. But these reduced by roughly $10 \%$ compared to Col-1 under reverse loading, as a result of the combined effect of freeze-thaw action and seawater corrosion.

In Col-3 and Col-4, which were subjected to a persistent eccentric compressive load with a magnitude of $0.2 P_{\mathrm{u}}$ and $0.35 P_{\mathrm{u}}$, respectively, and 300 times of freeze-thaw cycles and 100 times of seawater immersion, the horizontal tensile cracks induced by the persistent load closed upon the removal of the persistent loading system. During the low cyclic load test, these cracks reopened under the forward loading condition. No new horizontal crack was formed over the entire test due to forwarding loading. Besides, it was found that the yield load and the ultimate load of the forward loading case were lower than those of the reverse loading case. Under forward loading, the crush of concrete in the compression zone occurred earlier and was more severe than that under reverse loading. It is worth mentioning that the failure pattern of concrete compression zones under forward and reverse loading conditions differs considerably, or a clearly asymmetric failure pattern can be observed in Col-4 as shown in Figure 6.

As can be seen from Table 2, the yield load and ultimate load of Col-3 and Col- 4 under reverse loading were a little higher than those of Col-1 and Col-2. A possible explanation was that the columns with persistent load had an unrecoverable initial deformation before the cyclic test. This led to their smaller displacement amplitude because of the existence of the initial deformation during the cyclic test [21], which contributed to the increase of the yield load and ultimate load. However, at the same time, the environment factors, that is, freeze-thaw cycles and chloride corrosion, 
TABLE 2: Results of low cyclic load tests on reinforced concrete columns.

\begin{tabular}{|c|c|c|c|c|c|}
\hline Loading direction & Response & Col-1 & Col-2 & Col-3 & Col-4 \\
\hline \multirow{5}{*}{ Forward loading } & Yield load (kN) & 13.66 & 13.67 & 12.23 & 11.18 \\
\hline & $\delta_{\mathrm{y}}(\mathrm{mm})$ & 3.37 & 3.80 & 5.56 & 4.31 \\
\hline & Ultimate load $(\mathrm{kN})$ & 17.74 & 17.29 & 16.16 & 14.14 \\
\hline & $\delta_{\mathrm{p}}(\mathrm{mm})$ & 12.57 & 9.07 & 11.99 & 10.62 \\
\hline & $\delta_{\mathrm{u}}(\mathrm{mm})$ & 15.36 & 12.53 & 14.62 & 10.59 \\
\hline \multirow{5}{*}{ Reverse loading } & Yield load $(\mathrm{kN})$ & -17.12 & -15.30 & -9.73 & -17.27 \\
\hline & $\delta_{\mathrm{y}}(\mathrm{mm})$ & -8.50 & -8.86 & -17.31 & -8.32 \\
\hline & Ultimate load $(\mathrm{kN})$ & -19.69 & -17.14 & -17.81 & -20.13 \\
\hline & $\delta_{\mathrm{p}}(\mathrm{mm})$ & -14.89 & -12.68 & -17.31 & -12.92 \\
\hline & $\delta_{\mathrm{u}}(\mathrm{mm})$ & -19.42 & -17.42 & - & -18.08 \\
\hline
\end{tabular}

Note. $\delta_{\mathrm{y}}=$ the yield displacement; $\delta_{\mathrm{p}}=$ the displacement corresponding to the ultimate load; $\delta_{\mathrm{u}}=$ the displacement at $85 \%$ of the ultimate load on the descending portion of the load-displacement skeleton curve.

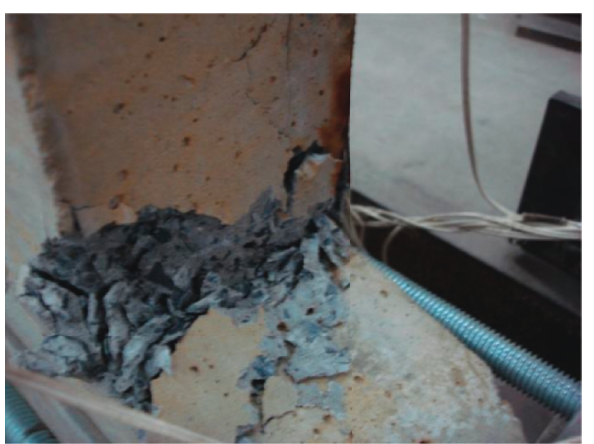

(a)

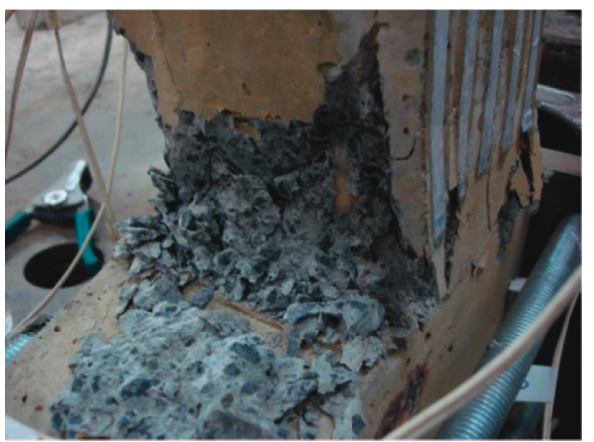

(c)

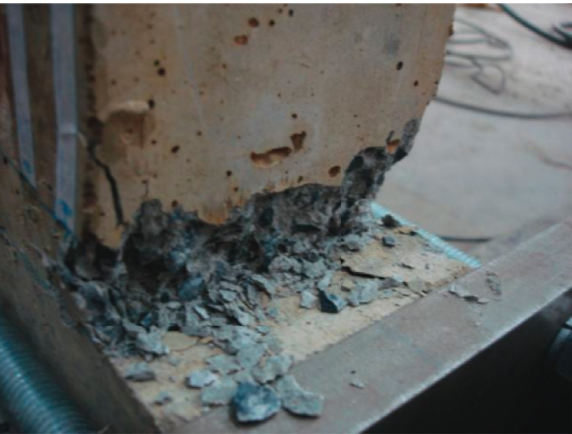

(b)

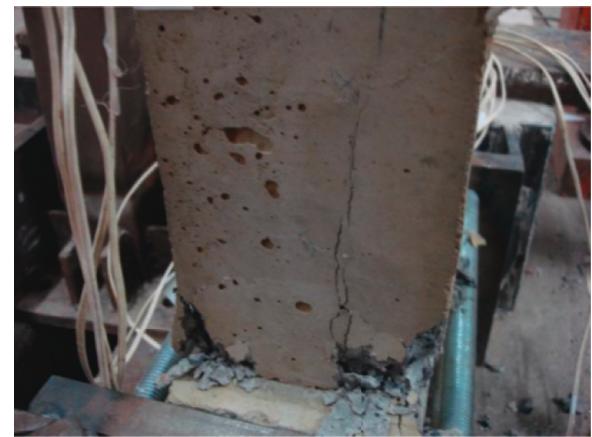

Col-4

(d)

Figure 6: Failure pattern of columns: forward loading $(a, c)$ and reverse loading $(b, d)$.

would aggravate the inner concrete structures causing the increase effect to be limited.

Therefore, it can be concluded that the synthesized effect of persistent load, freeze-thaw action, and seawater corrosion has a significant impact on the failure pattern of reinforced concrete columns, and an asymmetric failure pattern was observed.

3.2.2. Hysteretic Behavior. The hysteresis curves of Col-1 to Col-4 are depicted in Figure 7. For all four plots in the figure, the vertical axis represents the magnitude of the applied horizontal cyclic load, whereas the horizontal axis represents the horizontal displacement at the column top. It was illustrated in Figure 7 that when the controlling horizontal displacement at the column top was less than $8 \mathrm{~mm}$, the hysteresis curves were approximately linear in Col-1 and Col-2. As the column top horizontal displacement increased, the slope of the hysteresis curve and the column stiffness were all gradually decreased during the loading and unloading stages. Although Col-2 was subjected to 300 times of freeze-thaw cycles alternated with 100 times of seawater immersion, the hysteresis curve of Col-2 manifested symmetrical characteristics.

However, the hysteresis curves of Col-3 and Col-4 showed apparent asymmetry. The shape of the hysteresis loop corresponding to the forward loading condition differed considerably from that associated with the reverse loading case, that is, the shape of the latter was not full and the enclosed area was smaller. This implies that the presence 

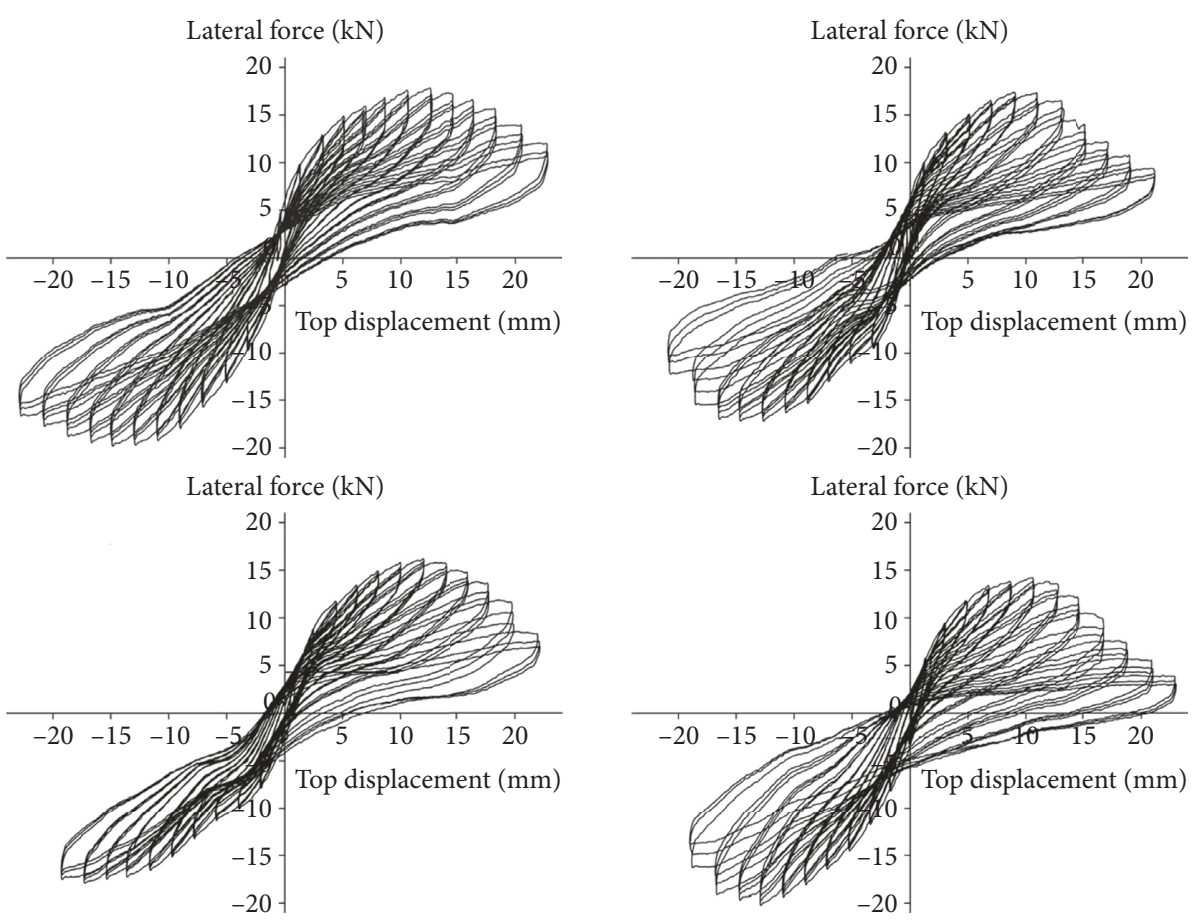

Figure 7: Hysteresis curves of reinforced air-entrained concrete column specimens: (a) Col-1; (b) Col-2; (c) Col-3; (d) Col-4.

of persistent load would have a significant impact on the hysteresis behavior of the column when columns were exposed to the multiple damage of freeze-thaw cycles and chemical corrosion.

The asymmetric shape of the hysteresis curve of Col-3 and Col- 4 could be caused by a number of reasons. First, the initial cracks induced by the persistent compressive load reduced the column stiffness when resisting forward loading. Second, the presence of load-induced cracks facilitated the penetration of seawater to reach and corrode the steel bars. It was further aggravated by the application of freeze-thaw cycles, resulting in a considerable degradation of bonding strength between the reinforcing bars and the surrounding concrete. This phenomenon was consistent with that observed in an earlier experiment by Poupard et al. [5]. Besides, the eccentric compressive load applied to Col-3 and Col-4 has sustained for 100 days. This would cause creep of concrete. Therefore, the reinforcing bars in the compression zone would be prestressed in compression, which in turn would increase the ultimate load of the specimen under the reverse loading condition. The apparent asymmetry and pinch of the hysteresis curves of Col-3 and Col-4 were believed to be caused by the combined effects of the above factors. More experimental study is needed to confirm the above speculation.

3.2.3. Load-Displacement Skeleton Curves. A loaddisplacement skeleton curve is an envelope which connects the peak points of the hysteresis curve corresponding to each loading cycle in the low cyclic loading test. The skeleton curves of Col-1 to Col-4 are illustrated in Figure 8.
As can be seen from Figure 8, the initial stiffness of Col-2 was nearly the same as that of Col-1 in the early stage of the low cyclic test. But the ultimate load and the ductility of Col2 appeared to be smaller than Col-1. A possible explanation was the difference in curing conditions. To be more specific, Col-2 was cured in the standard temperature and moisture conditions till the age of 23 days and then immersed in seawater for 4 days. In the next 100 days, it was subjected to the combined action of low temperature and chemical corrosion, that is, for every three freeze-thaw cycles, it was immersed in seawater for $12 \mathrm{~h}$. When the low cyclic test was performed between the age of 23 days and 128 days, the specimen was cured in a "moisture" environment which would be beneficial for the strength development of concrete, while Col-1 was left in the natural ventilation environment till the age of 128 days prior to the low cyclic test after being cured under the standard conditions for 28 days. For Col-3 and Col-4, as persistent eccentric compressive load increased, the ultimate load and stiffness under the forward loading condition decreased, while these increased under the reverse loading condition. The skeleton curves of these two specimens manifested apparent asymmetry, which was consistent with the phenomenon shown in Sections 3.2.1 and 3.2.2. Besides, the ultimate loads of Col-2 to Col-4 were all lower than that of Col-1.

3.2.4. Stiffness and Ductility. To evaluate the degradation of column stiffness, the secant stiffness of Col- 1 to Col- 4 under both forward and reverse loading conditions was plotted in Figure 9 against the displacement at the column top. Similar to what has been observed in Figure 8, the stiffness of Col-2 was found to be slightly higher than that of Col-1 when the 


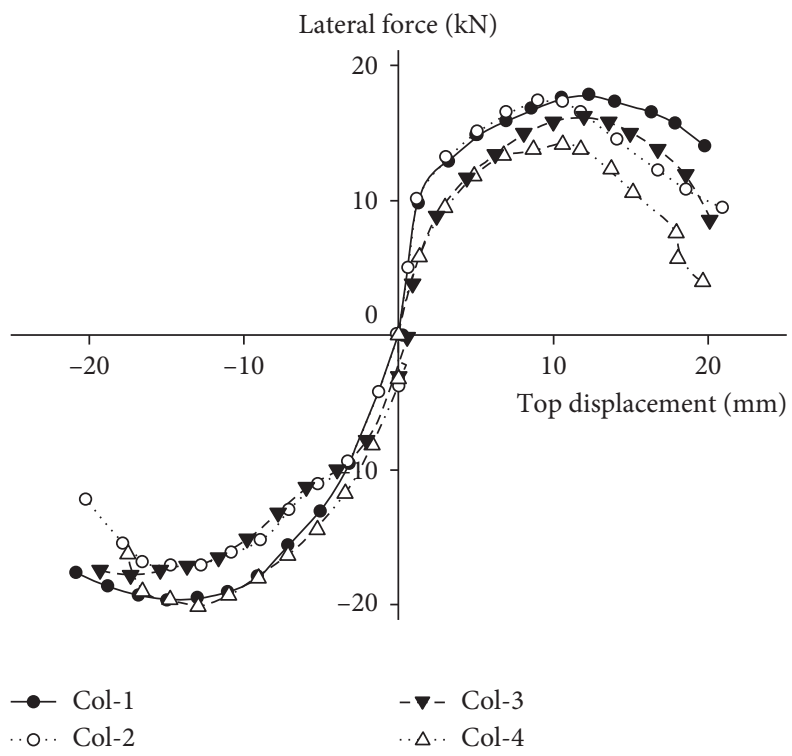

FIgURE 8: Skeleton curves of Col-1 to Col-4.

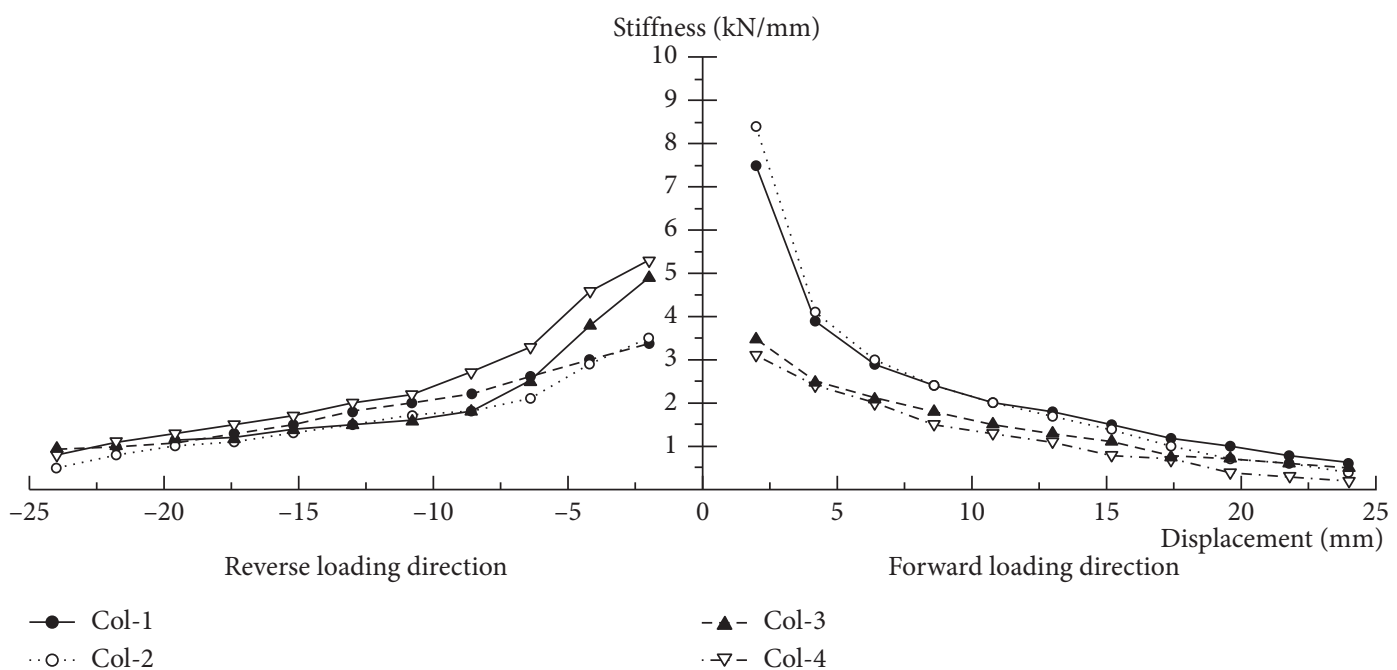

Figure 9: Stiffness degradation curve.

displacement at the column top was less than $10 \mathrm{~mm}$. As explained earlier, this phenomenon could be induced by the difference in the curing conditions of these two specimens. When the horizontal load was applied in the forward direction, Col-3 and Col-4, which were subjected to persistent eccentric compressive load, were found to be more flexible than Col-1 and Col-2. The higher the magnitude of the persistent eccentric compressive load was, the lower the column stiffness would be. Under the reverse loading condition, the initial stiffness of Col-3 and Col- 4 was found to be higher than that of Col-1 and Col-2, with that of Col-4 being the highest among the four columns. As has been explained in Section 3.2.2, columns in this study had initial damage causing the difference in the initial stiffness, which contributed to the asymmetrical stiffness degradation curve. Figure 9 also shows that the stiffness of all four column specimens was observed to reduce with the increase of column top displacement under both forward and reverse loading conditions.

Ductility coefficient was introduced to study the impact of the multiple-damage process on the ductility of the column specimens. If the horizontal displacement at the column top corresponding to the yield load is denoted as $\delta_{\mathrm{y}}$ and that corresponding to $85 \%$ of the ultimate load in the descending part of the skeleton curve as $\delta_{\mathrm{u}}$, the ductility coefficient was defined as the ratio between $\delta_{\mathrm{u}}$ and $\delta_{\mathrm{y}}$. The yield displacement $\delta_{\mathrm{y}}$ was determined by the energy method. The horizontal displacement of Col-1 to Col-4 corresponding to the yield load and $85 \%$ of the ultimate load in the descending part of the skeleton curve and their ductility coefficients are summarized in Table 3.

A comparison of the ductility coefficient between Col-1 and Col-2 revealed that if reinforced air-entrained concrete 
TAвLe 3: Summary of horizontal displacement at the column top under typical horizontal load and ductility coefficient.

\begin{tabular}{lcccccc}
\hline \multirow{2}{*}{ Specimen } & \multicolumn{4}{c}{ Forward loading } & \multicolumn{2}{c}{ Reverse loading } \\
& $\delta_{\mathrm{y}}(\mathrm{mm})$ & $\delta_{\mathrm{u}}(\mathrm{mm})$ & Ductility coefficient & $\delta_{\mathrm{y}}(\mathrm{mm})$ & $\delta_{\mathrm{u}}(\mathrm{mm})$ & Ductility coefficient \\
\hline Col-1 & 3.37 & 15.36 & 4.56 & -8.50 & -19.42 & 2.28 \\
Col-2 & 3.80 & 12.53 & 3.30 & -8.86 & -17.42 & - \\
Col-3 & 5.56 & 14.62 & 2.63 & -9.73 & - & -18.08 \\
Col-4 & 4.31 & 10.59 & 2.46 & -8.32 & -18.08 \\
\hline
\end{tabular}

Note. $\delta_{\mathrm{y}}=$ the yield displacement; $\delta_{\mathrm{u}}=$ the displacement at $85 \%$ of ultimate load on the descending portion of the load-displacement skeleton curve.

columns would be served in low temperature regions and also exposed to chemical attack, the combined effects of freeze-thaw cycles and chemical corrosion would degrade the ductility of the member, as reflected by the lower ductility coefficient of Col-2 under both forward and reverse loading conditions. However, if persistent eccentric compressive load was also part of the multiple damage mechanism, the persistent load could either degrade or enhance the ductility of the column depending on the direction of the cyclic load. Col-2 to Col-4 were subjected to 300 times of freeze-thaw cycles alternated with 100 times of seawater immersion, except the magnitude of the persistent eccentric compressive load applied to them was $0,20 \%$, or $35 \%$ of the bearing capacity of Col-0, respectively. Under the forward loading, the ductility coefficient of these three column specimens decreased as the persistent load increased. However, under reverse loading, the ductility coefficient of Col-4 was slightly higher than that of Col-2. Unfortunately, during the low cyclic load test of Col-3, the data of the forward loading case were analyzed first to obtain the corresponding portion of the hysteresis curve. The asymmetry of the curve under reverse loading was beyond expectation. Therefore, the horizontal displacement at the column top corresponding to $85 \%$ of the ultimate load in the reverse direction was not monitored (Figure 7). Nevertheless, efforts still have been made to measure the hysteresis curve of Col-4 in both loading directions, and it was indicated in Table 3 that although exposure to low temperature and corrosive environment could deteriorate the ductility of a reinforced concrete column member, the existence of persistent eccentric compressive load would be beneficial to the ductility if reverse load is applied.

3.3. Discussion. To have a clearer understanding of the factors that contributed to the performance degradation of reinforced air-entrained concrete columns subjected to the multiple-damage process, the deterioration of the mechanical properties of Col-2 to Col-4, in terms of the yield load, the ultimate load, and the ductility coefficient, is summarized in Table 4 by taking that of Col- 1 as the reference base.

As can be seen from Table 4, when forward load was applied, the ultimate load of the three column specimens decreased by $2.54 \%, 8.91 \%$, and $20.29 \%$, respectively, and the ductility coefficient decreased by $27.63 \%, 42.32 \%$, and $46.05 \%$, respectively. However, by reversing the load direction, a respective reduction of $12.95 \%, 9.55 \%$, and $-2.23 \%$ occurred for the ultimate load and $13.60 \%$ to $4.82 \%$ for the
TABle 4: Performance degradation of column specimens in comparison with Col-1.

\begin{tabular}{lcccc}
\hline Loading direction & Response & Col-2 & Col-3 & Col-4 \\
\hline \multirow{4}{*}{ Forward loading } & Yield load (\%) & -0.07 & 10.47 & 18.16 \\
& Ultimate load (\%) & 2.54 & 8.91 & 20.29 \\
& Ductility (\%) & 27.63 & 42.32 & 46.05 \\
\hline \multirow{3}{*}{ Reverse loading } & Yield load (\%) & 10.63 & 11.74 & -0.88 \\
& Ultimate load (\%) & 12.95 & 9.55 & -2.23 \\
& Ductility (\%) & 13.60 & - & 4.82 \\
\hline
\end{tabular}

ductility coefficient. In other words, under reverse loading, the ultimate load and the ductility coefficient of the columns increased with greater eccentric compressive persistent load. This clearly suggests that the structural behavior degradation of the studied columns depends on the direction of the cyclic load, of which the existence of persistent load would either degrade or enhance the load-bearing capacity and the ductility of the columns.

Data obtained from the current experimental study indicate that, with the increase of persistent eccentric compressive load, the adverse effect of freeze-thaw cycles and chemical corrosion on the behavior of reinforced concrete columns would be further promoted, the concrete cracks would be widened, and the corrosion of reinforcements at the locations of these cracks would become more severe. All these would lead to the reduction of column ultimate load, stiffness, and ductility when subjected to forward loading. These results are found to be consistent with those obtained from experimental studies by Poupard et al. [5] and Gong et al. [14]. As reviewed earlier, by inspecting the corrosion damage of a 40-year-old reinforced concrete beam served in the marine environment, Poupard et al. [5] found that a much more considerable corrosion occurred on steel bars in the tension zone than those in the compression zone. An apparent asymmetric hysteresis loop was observed by Gong et al. [14], where the low cyclic load test was conducted on sixteen electrochemically corroded and eccentrically loaded reinforced concrete columns.

\section{Conclusions}

An experimental study has been conducted to investigate the combined effect of freeze-thaw cycles and seawater corrosion on the cyclic response of reinforced air-entrained concrete columns subjected to persistent eccentric compressive load. The importance of studying the durability of reinforced concrete structures served in cold coastal seismic 
regions and accurate modeling of such service conditions in the study is highlighted. The following conclusions can be drawn from this study:

(i) When persistent eccentric compressive load was coupled with freeze-thaw cycles and seawater corrosion, the width of the initial cracks induced by the persistent load expanded as the number of freezethaw cycles increased. The fastest growth of crack width in this test was observed to occur during 102 to 201 times of freeze-thaw cycles.

(ii) Under the action of multiple damaging agents of freeze-thaw cycles, seawater immersion, and persistent eccentric compressive load, the hysteresis curve of reinforced air-entrained columns manifested apparent asymmetry. The effect of the persistent eccentric compressive load, when combined with the influence of freeze-thaw cycles and chemical attack, would deteriorate the performance of the column under the forward loading condition. The ultimate load, stiffness, and ductility of the column all decreased with a higher amount of persistent load. However, the existence of such persistent load was beneficial to the column performance when reverse load was applied.

\section{Conflicts of Interest}

The authors declare that there are no conflicts of interest regarding the publication of this paper.

\section{Acknowledgments}

This work was financially supported by the National Natural Science Foundation of China (Grant no. 51678021), the Academic Excellence Foundation of BUAA for Ph.D. Students, and the Open Project of State Key Laboratory of Subtropical Building Science, South China University of Technology (2016ZA03).

\section{References}

[1] P. P. Win, M. Watanabe, and A. Machida, "Penetration profile of chloride ion in cracked reinforced concrete," Cement and Concrete Research, vol. 34, no. 7, pp. 1073-1079, 2004.

[2] X. Wang, M. G. Stewart, and M. Nguyen, "Impact of climate change on erosion and damage to concrete infrastructure in Australia," Climatic Change, vol. 110, no. 3-4, pp. 941-957, 2012.

[3] A. Alhozaimy, R. R. Hussain, R. Al-Zaid, and A. Al-Negheimish, "Coupled effect of ambient high relative humidity and varying temperature marine environment on erosion of reinforced concrete," Construction and Building Materials, vol. 28, no. 1, pp. 670-679, 2012.

[4] H. Yalciner, O. Eren, and S. Sensoy, "An experimental study on the bond strength between reinforcement bars and concrete as a function of concrete cover, strength and erosion level," Cement and Concrete Research, vol. 42, no. 5, pp. 643-655, 2012.

[5] O. Poupard, V. L'Hostis, S. Catinaud, and I. Petre-Lazar, "Erosion damage diagnosis of a reinforced concrete beam after
40 years natural exposure in marine environment," Cement and Concrete Research, vol. 36, no. 3, pp. 504-520, 2006.

[6] B. Diao, Y. Sun, S. Cheng, and Y. Ye, "Effects of mixed erosion, freeze-thaw cycles, and persistent loads on behavior of reinforced concrete beams," Journal of Cold Regions Engineering, vol. 25, no. 1, pp. 37-52, 2011.

[7] X. Zheng, D. Bo, S. Yang et al., "Study of deterioration mechanism of concrete in multi-aggressive and freeze-thaw environment," Journal of Building Structures, vol. 31, no. 2, pp. 111-116, 2010.

[8] T. Pheeraphan and C. K. Y. Leung, "Freeze-thaw durability of microwave cured air-entrained concrete," Cement and Concrete Research, vol. 27, no. 3, pp. 427-435, 1997.

[9] W. M. Hale, S. F. Freyne, and B. W. Russell, "Examining the frost resistance of high performance concrete," Construction and Building Materials, vol. 23, no. 2, pp. 878-888, 2009.

[10] L. A. Montejo, J. E. Sloan, M. J. Kowalsky, and T. Hassan, "Cyclic response of reinforced concrete members at low temperatures," Journal of Cold Regions Engineering, vol. 22, no. 3, pp. 79-102, 2008.

[11] L. Giordano, G. Mancini, and F. Tondolo, "Reinforced concrete members subjected to cyclic tension and erosion," Journal of Advanced Concrete Technology, vol. 9, no. 3, pp. 277-285, 2011.

[12] J. Simon, J. M. Bracci, and P. Gardoni, "Seismic response and fragility of deteriorated reinforced concrete bridges," Journal of Structural Engineering, vol. 136, no. 10, pp. 1273-1281, 2010.

[13] X. Song, X. Gu, Y. Li, T. Chen, and W. Zhang, "Mechanical behavior of FRP-strengthened concrete columns subjected to concentric and eccentric compression loading," Journal of Composites for Construction, vol. 17, no. 3, pp. 336-346, 2013.

[14] J. Gong, W. Zhong, and G. Zhao, "Experimental study on lowcycle behavior of corroded reinforced concrete member under eccentric compression," Journal of Building Structures, vol. 25, no. 5, pp. 92-98, 2004.

[15] Q. Shi, X. Li, D. Niu et al., "Experimental study of bearing capacity of corroded reinforced concrete eccentric compressive members," Industrial Construction, vol. 31, no. 5, pp. 14-17, 2001.

[16] B. Shen, Y. Ye, B. Diao et al., "Mechanical performance and chloride diffusivity of cracked RC specimens exposed to freeze-thaw cycles and intermittent immersion in seawater," Advances in Materials Science and Engineering, vol. 2016, Article ID 5973467, 10 pages, 2016.

[17] Q. Li, Mechanical Behavior of Corroded RC Columns under Load and Environment, Zhejiang University, Hangzhou, China, 2015.

[18] B. Diao, J. Zhang, Y. Ye, and S. Cheng, "Effects of freeze-thaw cycles and seawater erosion on the behavior of reinforced airentrained concrete beams with persistent loads," Journal of Cold Regions Engineering, vol. 27, no. 1, pp. 44-53, 2013.

[19] J. Wu, N. F. PaPa, W. Zhang et al., "Chloride diffusivity and service life prediction of RC columns with sustained load under chloride environment," Construction and Building Materials, vol. 158, pp. 97-107, 2018.

[20] Z. Liu, B. Diao, and X. Zheng, "Effects of seawater corrosion and freeze-thaw cycles on mechanical properties of fatigue damaged reinforced concrete beams," Advances in Materials Science and Engineering, vol. 2015, Article ID 536487, 15 pages, 2015.

[21] S. Jie, Y. Shi-ping, W. Fei, and Y. Yang, "Experimental study on the fatigue behaviour of RC beams strengthened with TRC after sustained load corrosion," Construction and Building Materials, vol. 2017, no. 131, pp. 713-720, 2017. 


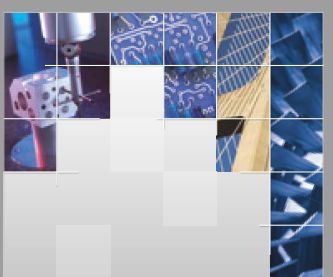

\section{Enfincering}
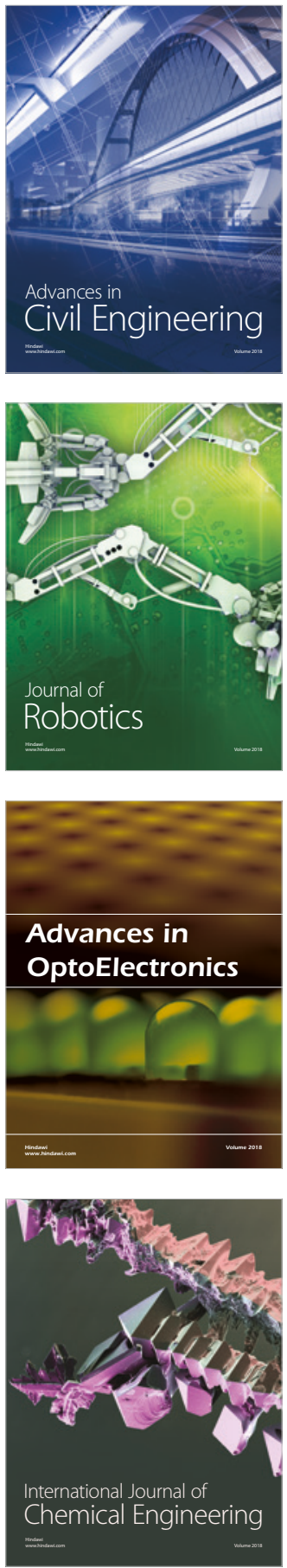

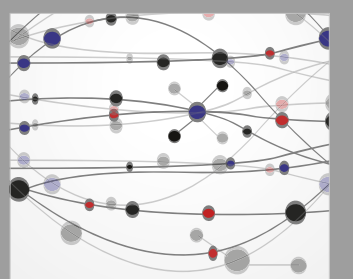

\section{Rotating \\ Machinery}

The Scientific World Journal

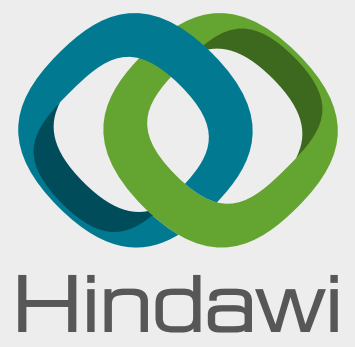

Submit your manuscripts at

www.hindawi.com
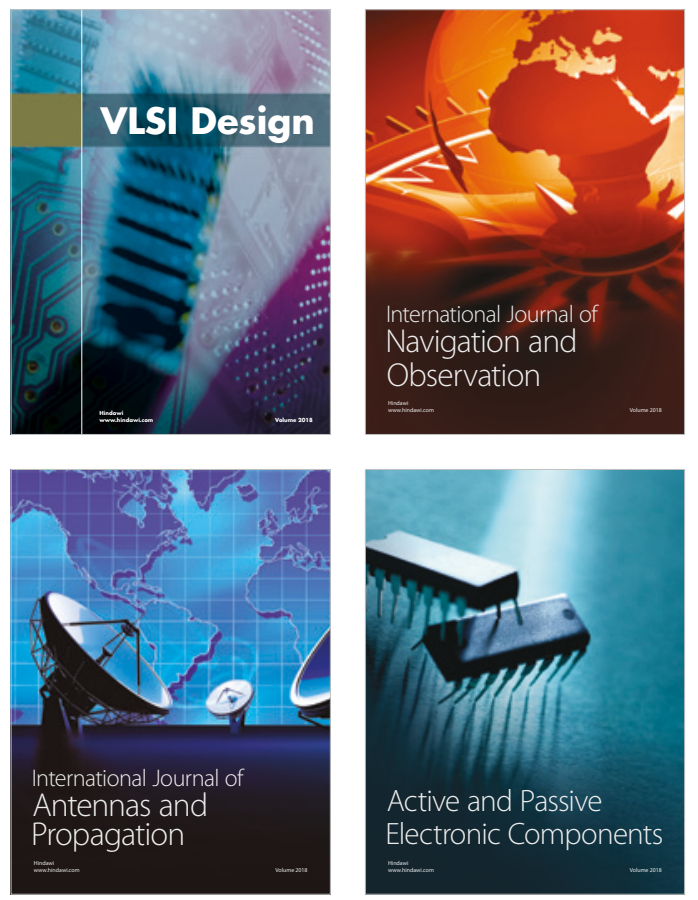
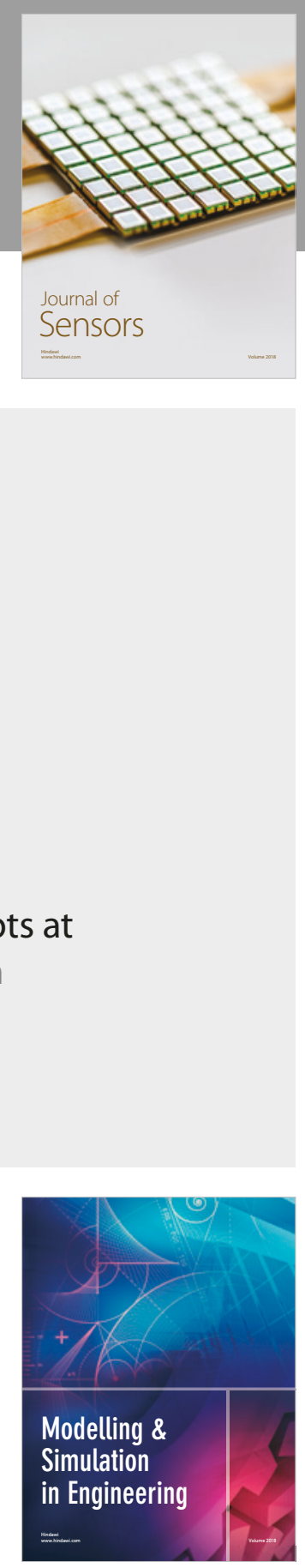

\section{Advances \\ Multimedia}
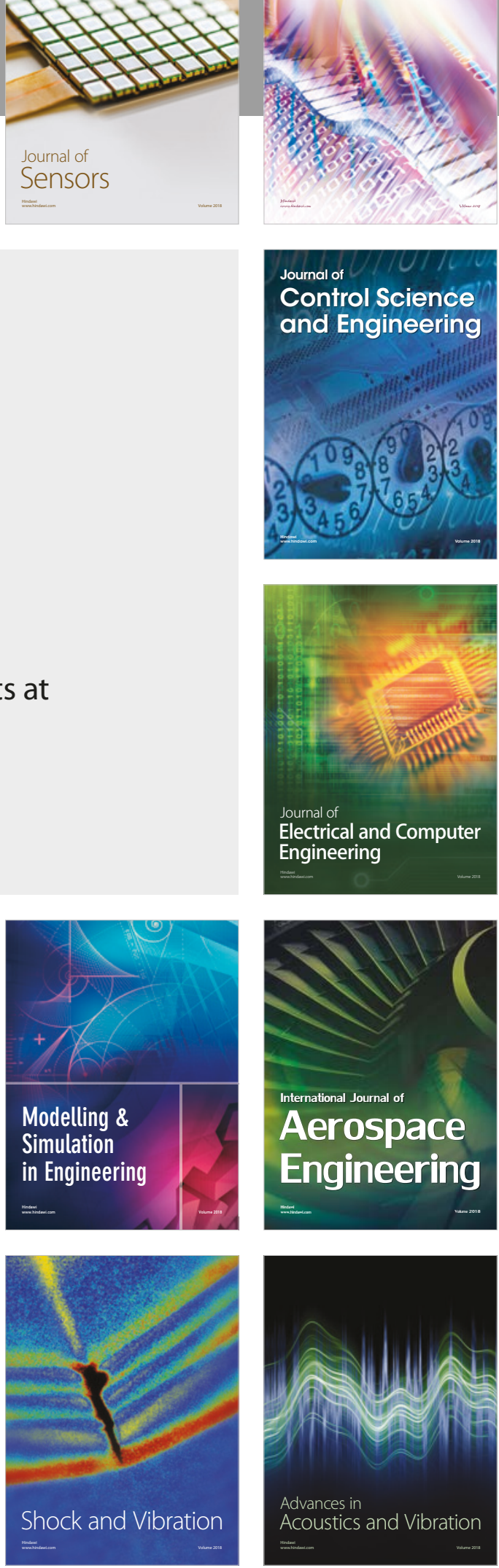